\title{
Extramedullary plasmacytoma of the colon: a case report
}

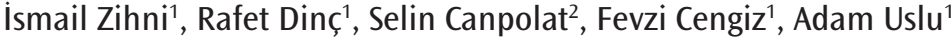

ABSTRACT

Extramedullary plasmacytoma is a rare cause of nonobstructive colonic masses, which is often disregarded. Plasmacytoma is a neoplastic proliferation of plasma cells; when systemic involvement occurs, the disease is named multiple myeloma. Extramedullary plasmacytomas comprise $4 \%$ of all plasma cell tumours and occur mainly in the upper respiratory tract; gastrointestinal system involvement is rare. In this case we describe a rare cause of gastrointestinal system mass: extramedullary plasmacytoma involving the left colon.

Key Words: Extramedullary plasmacytoma, multiple myeloma, colon neoplasms

\section{INTRODUCTION}

Multiple myeloma (MM) refers to a condition where malignant plasma cells are clonally increased in the bone marrow. It is a hematological, malignant tumor that is especially seen in adulthood, which is characterized by monoclonal gammopathy in the serum and/or urine and widespread osteolytic bone lesions. It constitutes $10 \%$ of all hematological malignancies (1). Multiple myeloma generally involves the bone marrow; however, it may also involve other sites.

The plasma cells are located in tissues (upper respiratory and gastrointestinal system mucosa) and lymphoreticular system organs (bone marrow, lymphatic gland, liver), and plasma cell neoplasms (plasmacytomas) originate from these cells (2). Plasmacytomas may cause either microscopic involvement or organ deformity and dysfunction (1). The disease is seen in three different clinical pictures; a) MM, in the presence of a systemic disease, b) extramedullary plasmacytoma (EMP), if there are no systemic signs along with an extramedullary tumor, c) solitary plasmacytoma, if there are no systemic signs along with a tumor localized in the medullary sites (3).

The aim of this case presentation was to report on primary extramedullary plasmacytoma of the colon, one of the various patterns of intra-abdominal extramedullary multiple myeloma that is rarely seen, and

'Clinic of General Surgery, İzmir Bozyaka Training and Research Hospital, İzmir, Turkey

${ }^{2}$ Clinic of Pathology, İzmir Bozyaka Training and Research Hospital, İzmir, Turkey

\section{Address for Correspondence İsmail Zihni \\ Clinic of General Surgery, Izmir Bozyaka Training and Research Hospital, İzmir, Turkey Phone: +90 5056422446 \\ e-mail: \\ ismailzihni@yahoo.com}

Received: . 12.2012

Accepted: 08.03.2013

Online Available Date: 30.08.2013

@C Copyright 2014 by Turkish Surgical Association

Available online at www.ulusalcerrahidergisi.org to outline its clinical progress and treatment.

\section{CASE PRESENTATION}

A fifty-four year old male patient presented to the emergency service of our hospital with complaints of abdominal pain and weakness. He has experienced abdominal pain for the past 4 months, mostly on the left side of the abdomen, with no changes in his intestinal habits, no rectal bleeding and no known health problems. On physical examination, bowel sounds were normal, there was no guarding or rebound tenderness, an approximately $10 \times 5 \mathrm{~cm}$ in size mass with regular borders was palpated in the lower left quadrant, the rectal exam and other system examinations were normal. His laboratory results revealed hemoglobin $9 \mathrm{~g} / \mathrm{dL}$, hematocrit $29.9 \%$, thrombocyte $440000 / \mathrm{mm}^{3}$, calcium $13.9 \mathrm{mg} / \mathrm{dL}_{\text {, phos- }}$ phorus $2.5 \mathrm{mg} / \mathrm{dL}$. No air-fluid levels were identified in the direct abdominal x-ray. On ultrasonography, a heterogeneous mass with the dimensions of approximately $11 \times 6 \times 4.5 \mathrm{~cm}$, with lobulated margins in which linear echogenicities pertaining to gas were observed in the left lumbar region close to the lower pole of the left kidney. On abdominal tomography, this mass was assessed to be malignant, due to infiltration of the surrounding fat tissue in a $13-14 \mathrm{~cm}$ segment distal to the splenic flexure and causing annular wall thickening (Figure 1,2). The bone structures were evaluated as normal in the thoracic and abdominal tomography scans.

There were no emergent pathologies, and the patient was followed up at the outpatient clinic. Colonoscopy revealed an inflamed, ulcerated polypoid mass annularly surrounding a 6-7 cm segment distal to the descending colon. The immunohistochemical (IHC) examination of the endoscopic biopsy was cytokeratin (weak, focal +), EMA(-), CD3(-), CK7(-), CK20(-), LCA(-), CD20 (-), CD99(-), synaptophysin(-), 


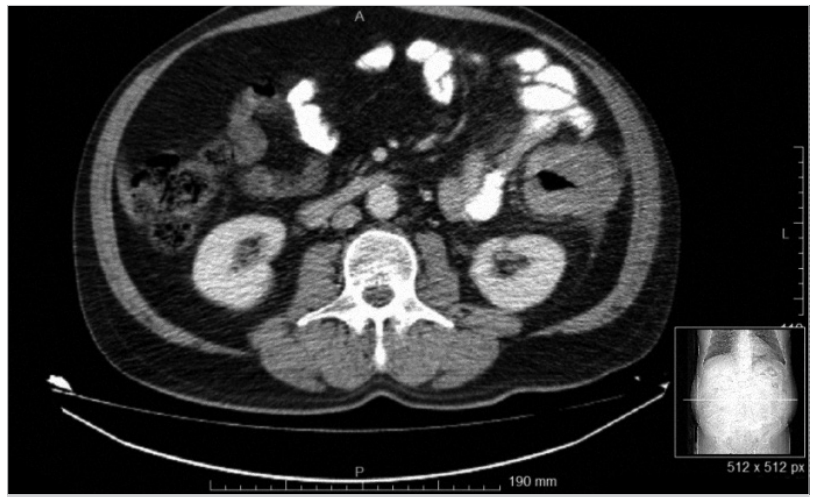

Figure 1. Computed tomography; colonic mass with infiltration of surrounding fat tissue and annular wall thickening

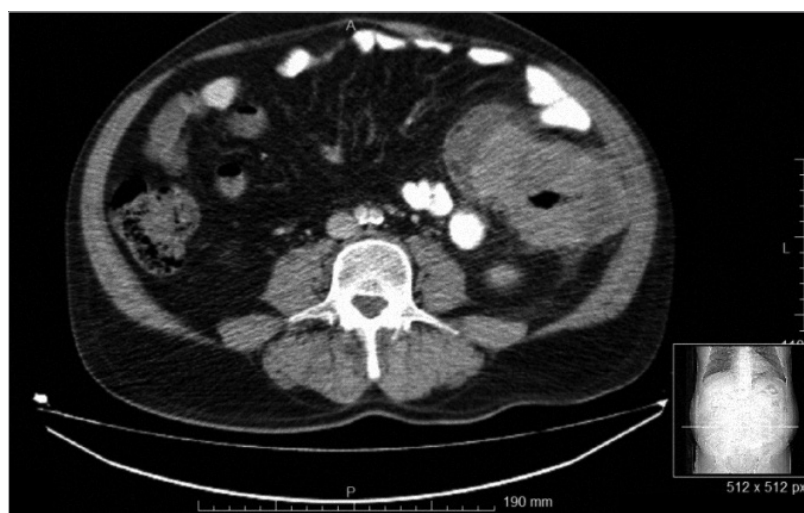

Figure 2. Computed tomography; colonic mass with infiltration of surrounding fat tissue and annular wall thickening, without bone involvement or obstruction

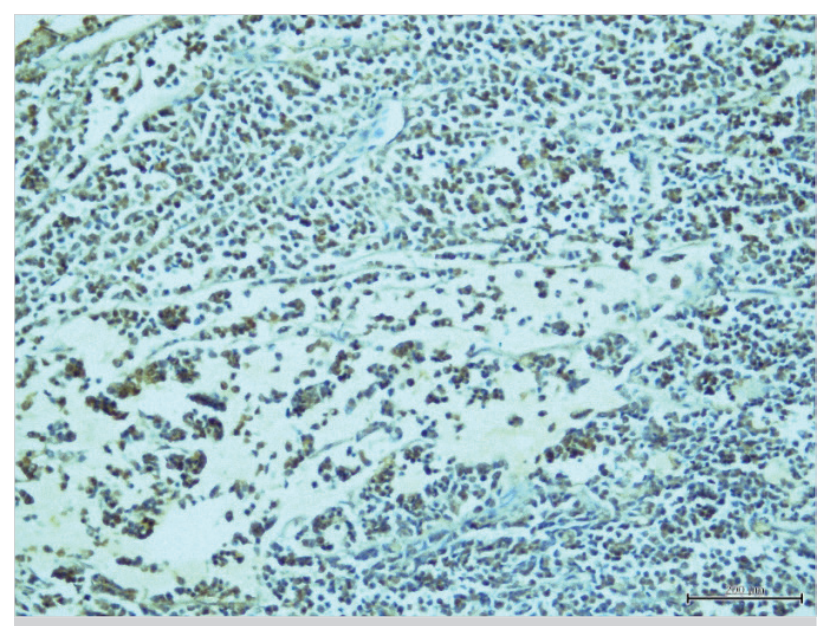

Figure 3. Microscopic evaluation (40×200): CD138 (+)) neoplastic plasma cells

chromogranin(-), and the result was reported as "undifferentiated malignant" tumor. No pathologies were identified in the scans for metastases; as for tumor markers, carcinoembryonic antigen and CA-19-9 were normal. The decision was taken to operate on the patient, who was informed on the surgical technique and a written informed consent form was received from him.

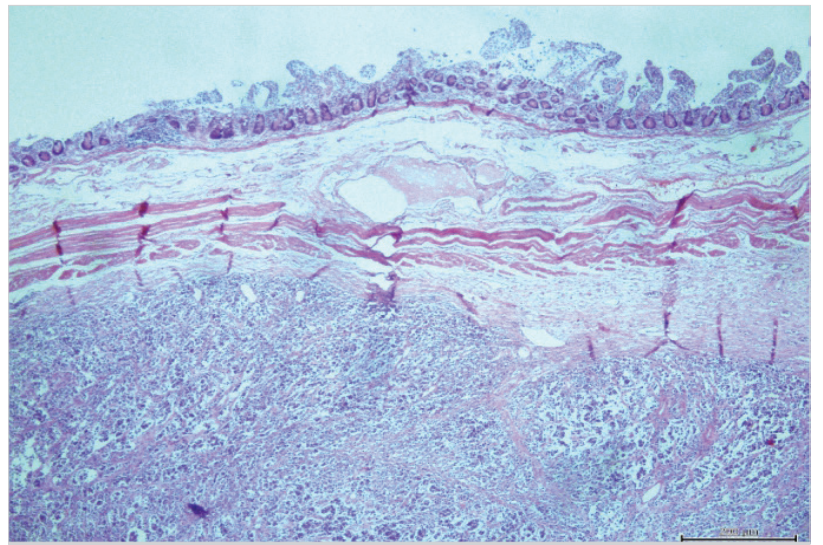

Figure 4. Microscopic evaluation ( $\mathrm{H}+\mathrm{E}, 40 \times 100)$ : neoplastic field on the serosal surface under muscularis propria on small bowel mucosa

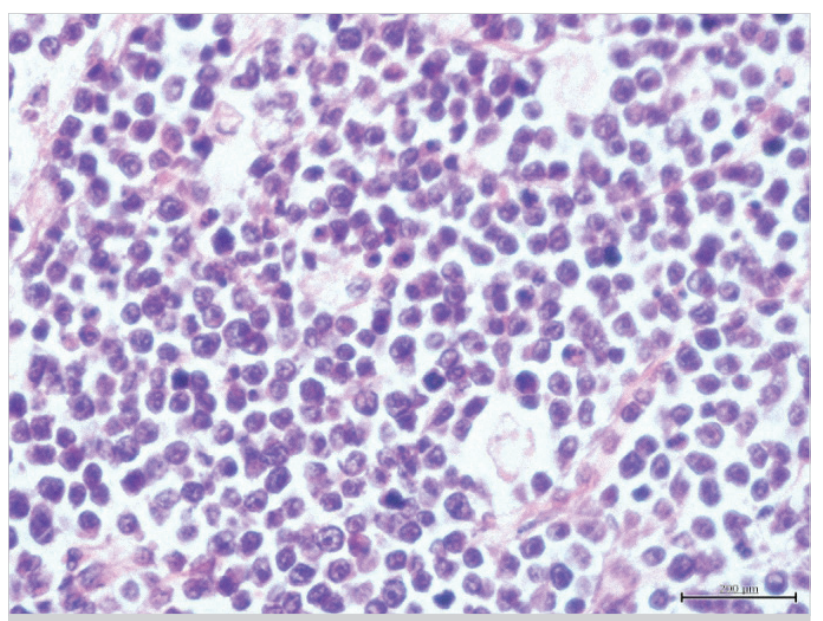

Figure 5. Microscopic evaluation $(\mathrm{H}+\mathrm{E}, 40 \times 600)$ : $\mathrm{H}$, scarce picnotic neoplastic fields with hyperchormatic nuclei in some neoplastic plasma cells

The patient was electively operated, the exploration revealed a tumoral mass of $20 \times 20 \mathrm{~cm}$ in the left lower quadrant, invading the abdominal wall and involving the small bowel between approximately $60 \mathrm{~cm}$ distal to ligament of Treitz and $100 \mathrm{~cm}$ to the ileocecal valve, the descending colon and causing a mass in the greater omentum. When the left Toldt fascia was opened, it was determined that the mass penetrated the psoas muscle and filled in the retroperitoneum. Following $\mathrm{R} 0$ resection, the small intestine and descending colon were anastomosed. The patient, who developed anastomotic leak, died on the thirty-fifth post-operative day due to sepsis.

According to the pathological examination, the lesion was reported as a submucosal plasma cell myeloma, $19 \times 14.5 \times 9 \mathrm{~cm}$ in size, with involvement of 4 out of 55 lymph nodes and negative surgical margins. The IHC examination results were as follows: CD38(+), CD138 (+), CD3(-), lambda(+), kappa(+), NSE focal(+), Ki67 \%2(+), CD99(-), CyclinD1(-), CK20(-), CD20(-), LCA(-), CD5(-), chromogranin(-) (Figure 3-5).

\section{DISCUSSION}

It is not clear how lymphocytes select certain organs or tissues for development a tumor, however, they may be located in anywhere including rare localizations as seen in our case. 
Extramedullary plasmacytomas are observed in only 3-5\% of plasma cell diseases (4). They frequently involve the nasopharynx or upper respiratory tract, colonic plasmacytomas are rare localizations of myelomas with less than 25 cases reported in the literature $(5,6)$. Nevertheless, adequate clinical and histopathological data as well as other details are available in only seven of these cases (7). The cause of plasma cell neoplasms is not clear, however, they are more often in men and are mostly seen in $4^{\text {th }}-7^{\text {th }}$ decades (4). These rare cases do not have any specific signs; the pain observed in our case is the most frequent non-specific sign, the signs reported in the literature include diarrhea, changes in bowel habits, rectal bleeding, large intestine obstruction and intussusception $(5,6,8)$. However, their clinical course is worse than adenocarcinomas (4).

Radiological imaging of the mass as an incomplete obstruction in the abdominal tomography scan, as in our case, is rare and it is often reported as an obstructive polypoid lesion, however, they may be confused with various diseases (4). The endoscopic biopsy of our case was histologically reported as undifferentiated carcinoma, since the typical concentrations of submucosal monoclonal plasma cells was not observed. As a next step, radiologic and endoscopic systemic screening of plasmacytoma (serum protein electrophoresis, urinary immunoelectrophoresis, immunofixation, bone scan, bone marrow biopsy-aspiration) could not be performed before and after surgery due to death of the patient. Considering that extramedullary plasmacytoma may developed prior to, during and following MM, the present hypercalcemia and 4 metastatic lymphatic nodules may be indicators of MM that would have developed in the follow-up of the disease.

There are no definitive treatment guidelines for colonic EMP, since they are generally operated on a preliminary diagnosis of adenocarcinoma causing an obstructive segment, as in our case. Radiotherapy is considered adequate for local control of the disease, while chemoterapy does not have an impact (4). However, systemic chemotherapy is the first option in EMP cases with bone involvement, or in reducing the size of primary tumors close to vital organs $(4,9)$. Surgical treatment with or without radiotherapy is often the preferred method, and enables curative treatment especially in primary colon EMPs (4).

\section{CONCLUSION}

Primary colon plasmacytoma is a rare clinical entity that may mimic colon tuberculosis or inflammatory bowel disease. As in our case, it may also mimic a primary colon tumor resulting in colonic obstruction. Therefore, multiple myeloma or its subgroup, EMP, should also be taken into consideration in the preoperative evaluation. The attention of the surgeon as well as the radiologist and pathologist would contribute significantly to the diagnosis and treatment planning in the pre-operative period.

Informed Consent: Written informed consent was obtained from patients who participated in this case.

Peer-review: Externally peer-reviewed.

Author Contributions: Concept - I.Z., R.D., F.C., S.C., A.U.; Design - I.Z., F.C.; Supervision - I.Z., R.D., F.C., S.C., A.U.; Funding - I.Z., R.D.; Materials I.Z., R.D.; Data Collection and/or Processing - I.Z., R.D., F.C., S.C.; Analysis and/or Interpretation - I.Z., F.C.; Literature Review - I.Z., F.C.; Writer - I.Z., F.C.; Critical Review - I.Z., R.D., A.U.; Other - F.C., A.U.

Conflict of Interest: No conflict of interest was declared by the authors.

Financial Disclosure: The authors declared that this study has received no financial support.

\section{REFERENCES}

1. Chang H, Chou WC, Lee SY, Huang JY, Hung YH. Myelomatous pleural effusion in a patient with plasmablastic myeloma: a case report. Diagn Cytopathol 2009; 37: 205-207. [CrossRef]

2. Patlas M, Khalili K, Dill-Macky MJ, Wilson SR. Spectrum of imaging findings in abdominal extraosseous myeloma. AJR Am J Roentgenol 2004; 183: 929-932. [CrossRef]

3. Cotran R, Kunar V, Robbins S, eds. Robbins Pathologic Basis of Disease. 4th ed. Philadelphia: W.B. Saunder's Co., 1989: 739-743.

4. Lattuneddu A, Farneti F, Lucci E, Garcea D, Ronconi S, Saragoni L. A case of primary extramedullary plasmacytoma of the colon. Int J Colorectal Dis 2004; 19: 289-291. [CrossRef]

5. Kakati BR, Krishna K, Krishna SG, Sharma SG, Sanathkumar N, Rego RF. Extensive extramedullary disease involving the colon in multiple myeloma: a case report and review of literature. J Gastrointest Cancer 2012; 43: 379-381. [CrossRef]

6. Islam SR, Attaya MN, Parupudi S, Islam EA, D'Cunha N, Labib S, et al. Sigmoid plasmacytoma mimicking colon cancer in a patient with multiple myeloma: case report and review of literature. Gastrointest Endosc 2010; 71: 655-657. [CrossRef]

7. Gupta V, Nahak B, Sakhuja P, Agarwal AK, Kumar N, Mishra PK. Primary isolated extramedullary plasmacytoma of colon. World J Surg Oncol 2007; 5: 47. [CrossRef]

8. Pacheco DC, de Solorzano MM, Lazaro EQ, Alvarez Cl, Torre LR. Extramedullary plasmacytoma of the colon: a rare cause of gastrointestinal bleeding. Endoscopy 2009; 41: 306-307. [CrossRef]

9. Kyle RA, Rajkumar SV. Multiple myeloma. N Engl J Med 2004; 351: 1860-1873. [CrossRef] 